\title{
IUCN
}

\section{An Introduction to the IUCN Red List of Ecosystems:}

The Categories and Criteria for Assessing Risks to Ecosystems

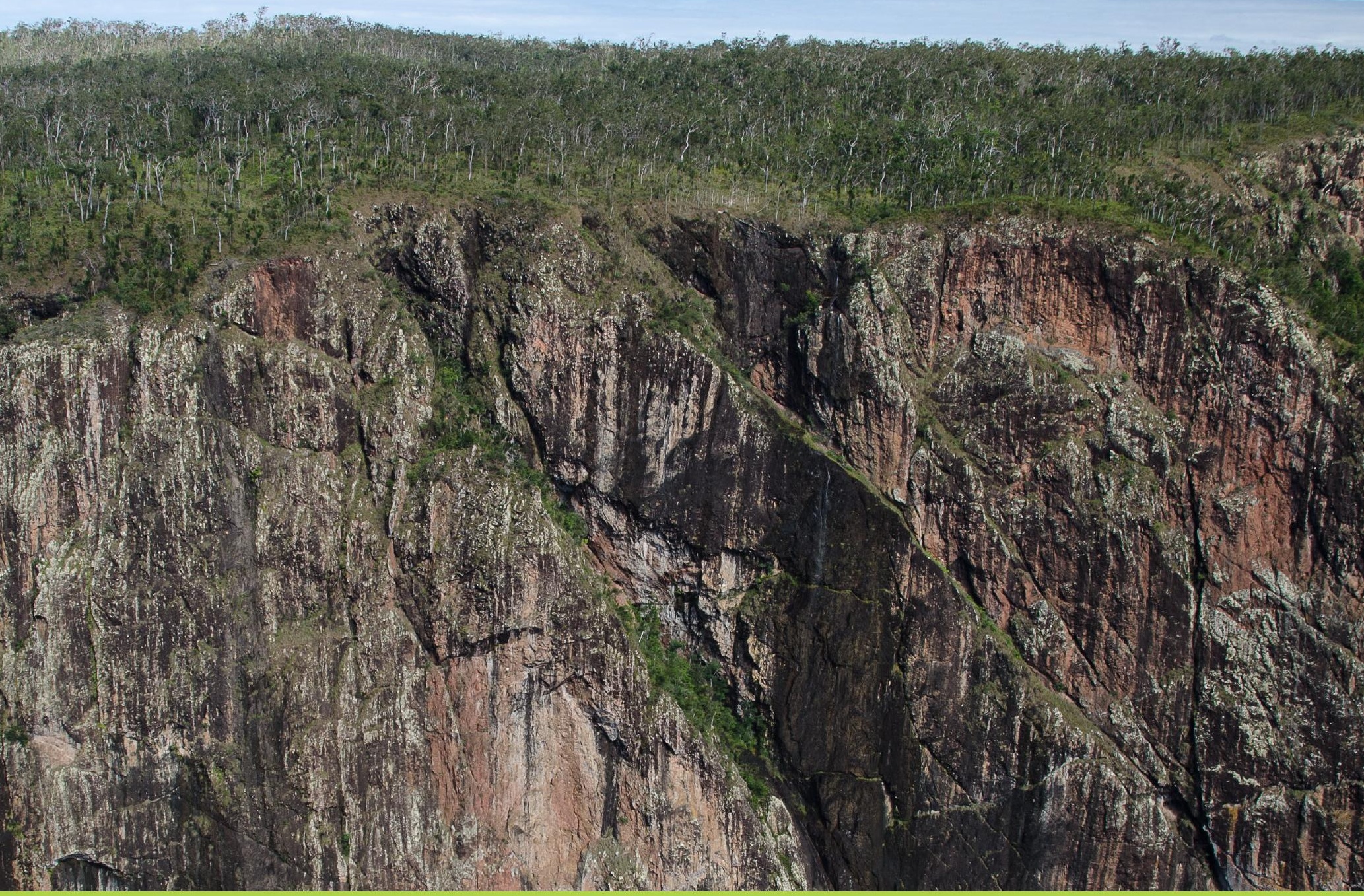


ERRATUM

Typo corrections were made on the following pages:

- Page 3, in Figure 2: "abiotic" corrected to "biotic" in reference to Criterion D - Page 14, in the table in Annex 2: "abiotic" corrected to "biotic" in reference to Criterion D 


\section{An Introduction to the IUCN Red List of Ecosystems:}

The Categories and Criteria for Assessing Risks to Ecosystems 
The designation of any geographical entities in this booklet, and the presentation of the material, do not imply the expression of any opinion whatsoever on the part of IUCN concerning the legal status of any country, territory, or area, or of its authorities, or concerning the delimitation of its frontiers or boundaries.

The views expressed in this publication do not necessarily reflect those of IUCN.

Published by: $\quad$ IUCN, Gland, Switzerland

Copyright: $\quad$ C 2016 International Union for Conservation of Nature and Natural Resources

An Introduction to the IUCN Red List of Ecosystems: The Categories and Criteria for Assessing Risks to Ecosystems is an open access publication licensed under a Creative Commons AttributionNonCommercial-NoDerivatives 4.0 International (CC BY-NC-ND 4.0).

Reproduction of this publication for educational or other non-commercial uses is authorized without prior written permission from the copyright holder provided the source is fully acknowledged. Reproduction of this publication for resale or other commercial purposes is prohibited without prior written permission of the copyright holder.

ISBN: $\quad 978-2-8317-1787-6$

DOI: http://dx.doi.org/10.2305/IUCN.CH.2016.RLE.2.en

Citation: $\quad$ IUCN (2016). An Introduction to the IUCN Red List of Ecosystems: The Categories and Criteria for Assessing Risks to Ecosystems. Gland, Switzerland: IUCN. vi + 14pp.

Cover photo: $\quad$ Dry forest ecosystem Queensland, Australia. (c) Nick Murray (front-back). All photographs used in this publication remain the property of the original copyright holder. Photographs should not be reproduced or used in other contexts without written permission from the copyright holder.

Design \& layout: Gordon Arara (IUCN Publications Unit, Nairobi)

Available from: $\quad$ IUCN (International Union for Conservation of Nature)

Global Ecosystem Management Programme

Rue Mauverney 28

1196 Gland

Switzerland

Tel +41229990000

Fax +41229990002

www.iucn.org/publications

This introduction is freely available online on https://portals.iucn.org/library/node/45958 and the IUCN Red List of Ecosystems website (www.iucnrle.org). This introduction is a 'living document' and will be updated periodically. 


\section{Table of Contents}

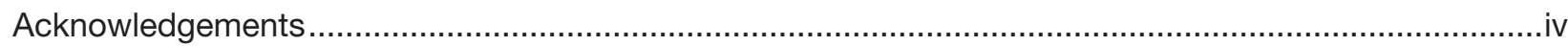

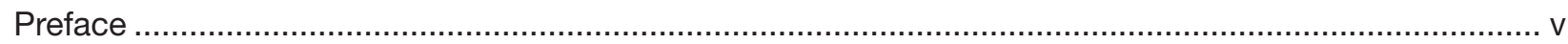

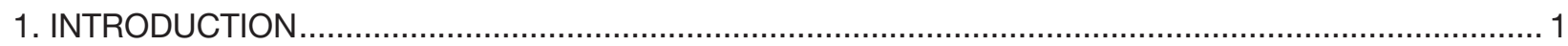

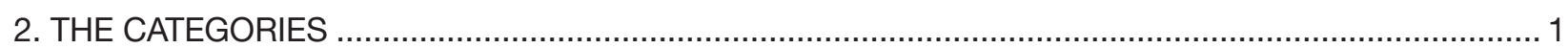

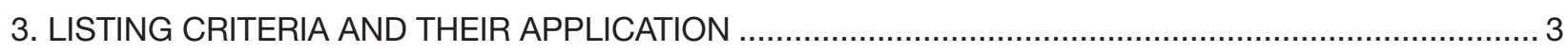

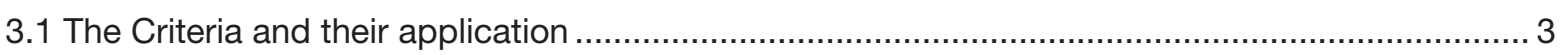

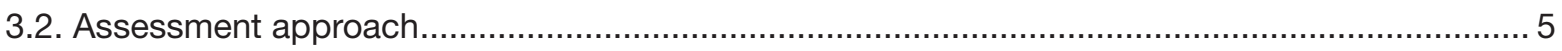

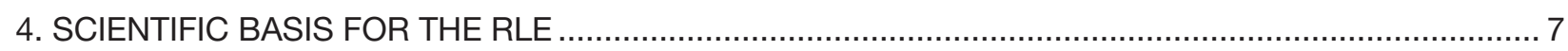

4.1 Ecosystem types: the units and scope of assessment ............................................................ 7

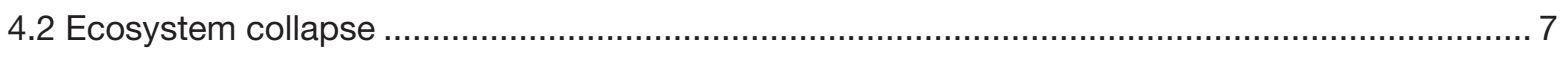

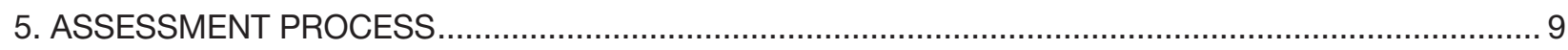

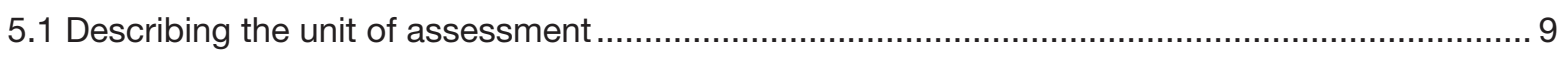

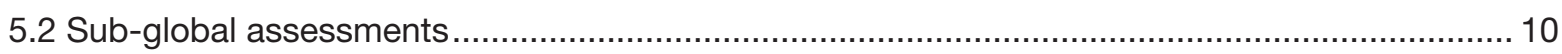

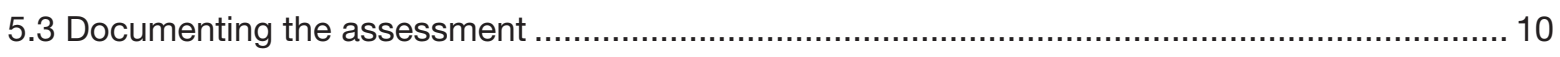

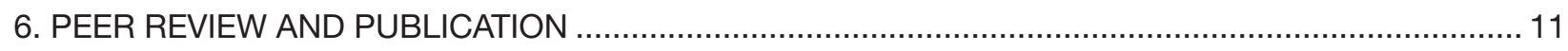

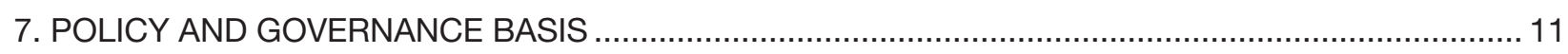

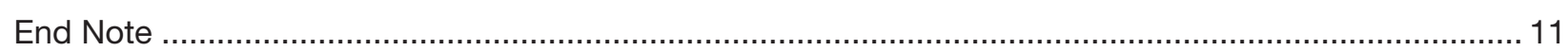

Annex 1: Key references for further information ............................................................................ 12

Annex 2. IUCN Red List of Ecosystems Criteria, Version 2.1 …....................................................... 13

Figures:

Figure 1. Structure of the IUCN Red List of Ecosystems categories .................................................. 2

Figure 2. Mechanisms of ecosystem collapse and symptoms of collapse risk ....................................... 3

Figure 3. Process for assessing the risk of collapse of an ecosystem type.............................................. 6

Figure 4. An Example of a conceptual model of the risk assessment of the Meso-American Reef. (EAC: Epilithic Algal Communities) ............................................................ 9

Boxes:

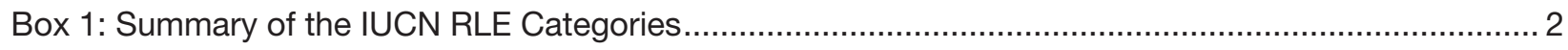

Box 2. Distribution map of the Yellow Sea tidal flat ecosystem (Criterion A and B) ................................. 4

Box 3. Assessing environmental degradation (Criterion C)................................................................... 4

Box 4. Assessing disruption of biotic processes (criterion D) .............................................................. 5

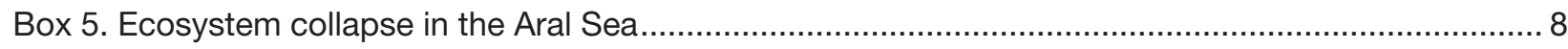




\section{About IUCN}

IUCN is a membership Union uniquely composed of both government and civil society organisations. It provides public, private and non-governmental organisations with the knowledge and tools that enable human progress, economic development and nature conservation to take place together.

Created in 1948, IUCN is now the world's largest and most diverse environmental network, harnessing the knowledge, resources and reach of 1,300 Member organisations and some 15,000 experts. It is a leading provider of conservation data, assessments and analysis. Its broad membership enables IUCN to fill the role of incubator and trusted repository of best practices, tools and international standards.

IUCN provides a neutral space in which diverse stakeholders including governments, NGOs, scientists, businesses, local communities, indigenous peoples organisations and others can work together to forge and implement solutions to environmental challenges and achieve sustainable development.

Working with many partners and supporters, IUCN implements a large and diverse portfolio of conservation projects worldwide. Combining the latest science with the traditional knowledge of local communities, these projects work to reverse habitat loss, restore ecosystems and improve people's well-being.

www.iucn.org

https://twitter.com/IUCN/

\section{Acknowledgements}

IUCN gratefully acknowledges the dedication and efforts of the hundreds of scientists and practitioners who have contributed to the scientific development and practical testing of the IUCN Red List of Ecosystems Categories and Criteria since 2008. These experts have cumulatively participated in over 50 meetings and workshops in more than 20 countries around the world, and have also submitted comments and suggestions remotely. IUCN is grateful to those who reviewed this document including Ali Raza, Jonathan Davies, Radhika Murti, Kaia Boe, Michelle Kimeu, Akshay Vishwanath, David Keith, Jon Paul Rodriguez, Nick Murray, Lucie Bland and Edmund Barrow. Their comment and critique helped make the text understandable for a wide range of audiences. To all, IUCN is most indebted.

The work on the IUCN RLE has been made possible through generous support from: Agence Française de Développement, Australian Research Council, Conoco-Philips, Embassy of the Netherlands in Brazil, European Commission, Gordon and Betty Moore Foundation, IUCN Netherlands National Committee, IUCN Secretariat, IUCN Commission on Ecosystem Management (CEM), MAVA Foundation, New South Wales Office of Environment and Heritage, and South Australian Department of Environment, Water and Natural Resources. 


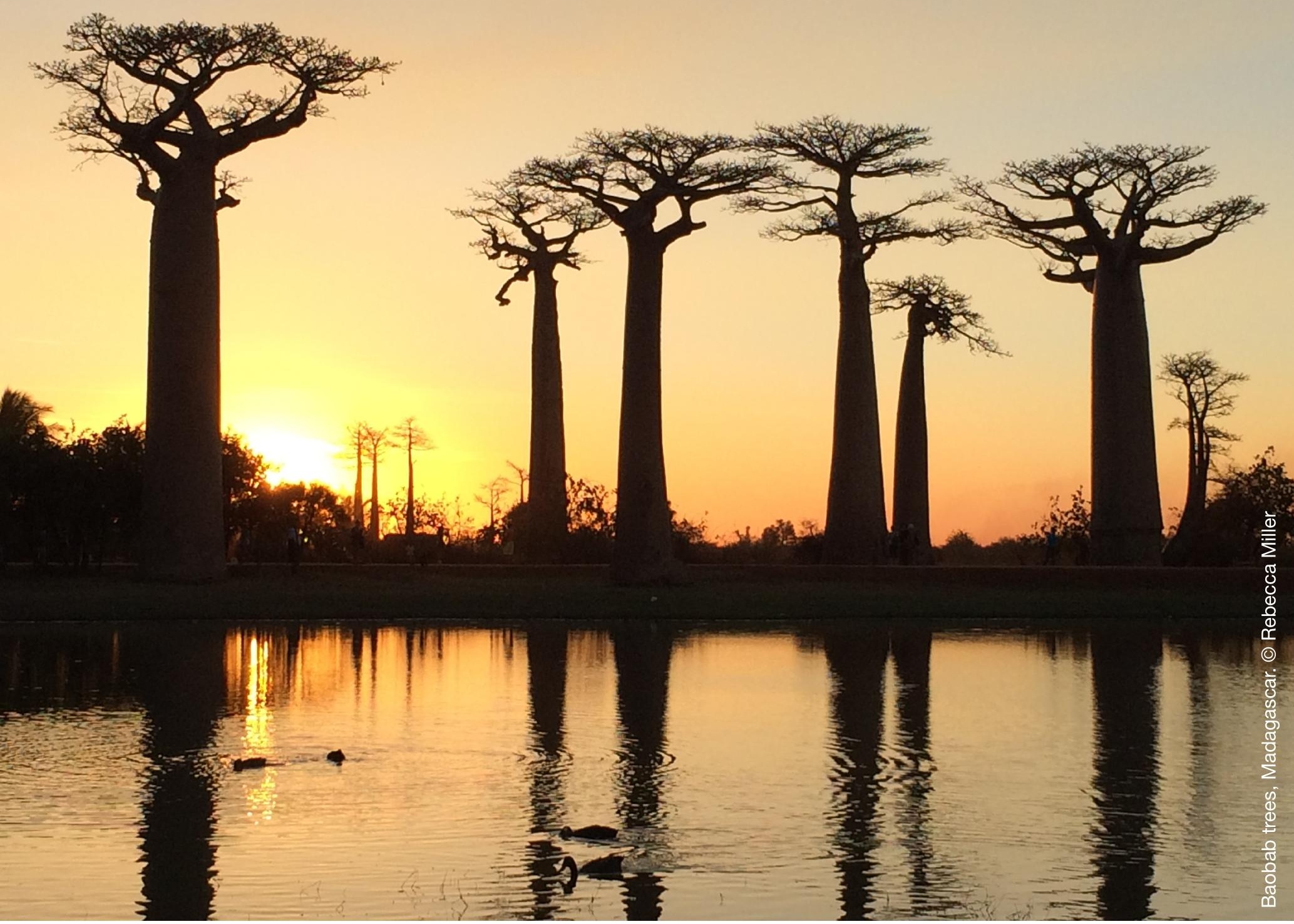

\section{Preface}

This Introductory Guide draws on a number of key IUCN Red List of Ecosystems (RLE) papers, case studies and background documents to provide a practical introduction to the RLE. It targets those who wish to gain a deeper understanding of the RLE as a risk assessment tool and those who wish to learn more about its possible applications in implementing conservation action. This document draws heavily on Version 1 of the Guidelines for the application of the IUCN Red List of Ecosystems Criteria and Categories ${ }^{1}$.

Please note that this introduction to RLE does include a few key references, but additional references and background materials are to be found in Annex 1. We encourage readers to explore the RLE web-site (www. iucnrle.org) where key documents, tools, case studies, and further information are provided in English, French and Spanish.

This introduction provides an overview of the scientific foundations supporting the RLE categories and criteria. The basis of the IUCN RLE is a set of eight categories and five criteria that provide a consistent method for assessing the risk of ecosystem collapse ${ }^{2}$. In particular, this introduction explains the RLE in "an informed lay person's" language. It is does not provide detailed information on the scientific foundations that underpin RLE (see www.iucnrle.org).

1 Those details can be found on the RLE web site (www.iucnrle.org). To carry out ecosystem assessments, the readers are directed to Version 1 of the Guidelines (https://portals.iucn.org/library/node/45794) Collapse is a transformation of identity, a loss of defining features, and a replacement by a different ecosystem type 


\section{INTRODUCTION}

Ecosystems across the globe continue to be degraded and this undermines their capacity to support life. The IUCN Red List of Ecosystems (RLE) is a set of categories and criteria for assessing the risks to ecosystems and to focus attention on where ecosystems are threatened. It is part of a growing toolbox for analysing risks to biodiversity at all scales and it aims to support conservation, resource use and management decision making by identifying ecosystems most at risk. The RLE complements the IUCN Red List of Threatened Species ${ }^{\mathrm{TM}}$, and is designed to be: a) applicable in a consistent way for all ecosystem types and geographical areas, b) transparent and scientifically rigorous, and c) easily understood by policy makers and the public - both in conservation and land/water use. The RLE will assess the global status of all the world's terrestrial, marine, freshwater and subterranean ecosystems. As part of this process a global ecosystem classification will be developed, based on existing national and other types of classification. It will support the development of national and regional Red Lists of ecosystems to inform conservation and land/water use as part of sustainable development planning.

The goal of the RLE is to support conservation and decision making for land and water use and management by identifying ecosystems that are not at risk (Least Concern) and those most at risk (hence a Red List). By assessing the risks of biodiversity loss at the ecosystem level, the RLE can account for broad scale ecological processes and the important interactions among species that keep ecosystems functioning.

The RLE is a risk assessment tool; as such it will only be as good as how it is applied in conservation and land/water use planning, decision making and action. The RLE is ideally suited for conservation agencies to engage at a national level, in terms of increasing knowledge on conservation status (based on sound science) and subsequently assisting with the decision making and priority setting process for action at technical, political and financing levels. The RLE has the potential to be an important and cost-effective tool to assist countries with environmental monitoring and their international reporting requirements (e.g. SDGs, Aichi Targets) in a manner that is comparable over time and repeatable; for example being able to carry out repeat RLEs every 5 years (at relatively low cost). In terms of the SDGs ${ }^{3}$, the RLE can contribute to especially Goal 14 and $15^{4}$, while it is also an important tool for assisting in reporting on the Aichi $\operatorname{Targets}^{5}(5,11,12,14$, and 15).

By integrating different conservation tools (e.g. with the IUCN Red List of Threatened Species ${ }^{\mathrm{TM}}$, Key Biodiversity Areas, and World Database on Protected Areas), the RLE provides us with a powerful basis to move to a more strategic conservation planning focus and brings conservation into macro-economic planning, national land/water use, and fiscal planning. This will provide the data and evidence that are so badly needed to tackle the challenges faced by humanity today and into the future (e.g. land and resource use pressures, climate change, degradation, conversion, and invasive species).

We hope that this introduction to the RLE will provide readers with an informed perspective on the RLE and a desire to know more. We highlight (Annex 1) other key references, as there is a rapidly growing literature base for the RLE. This will help the reader explain the RLE to others from the ecosystem and national, to the regional and global levels, and across disciplines. If you plan to undertake a full RLE, please refer to these more detailed documents as this Introduction will not suffice for your needs.

\section{THE CATEGORIES}

The RLE has eight categories: Collapsed (CO), Critically Endangered (CR), Endangered (EN), Vulnerable (VU), Near Threatened (NT), Least Concern (LC), Data Deficient (DD), \& Not Evaluated (NE, Figure 1, Box 1). The first 6 categories are ordered in decreasing risks of collapse. The Categories DD or NE do not reflect a level of risk. The categories $\mathrm{CR}$, EN or VU indicate threatened ecosystems and are defined by quantitative criteria. These categories are nested from less to greater risk, for example. An ecosystem type that meets a criterion for Critically Endangered will also meet the criteria for Endangered and Vulnerable categories (in which risk is less severe). The three threatened categories (CR, EN or VU) are jointly referred to as threatened, and are complemented by several qualitatively defined categories that accommodate:

(i) Near Threatened (NT) that almost meet the criteria for Vulnerable;

(ii) Least Concern (LC) that meet none of the criteria for Vulnerable;

(iii) Data Deficient (DD) for which too few data exist to apply any criterion; and

(iv) Not Evaluated (NE) that have not been assessed. 


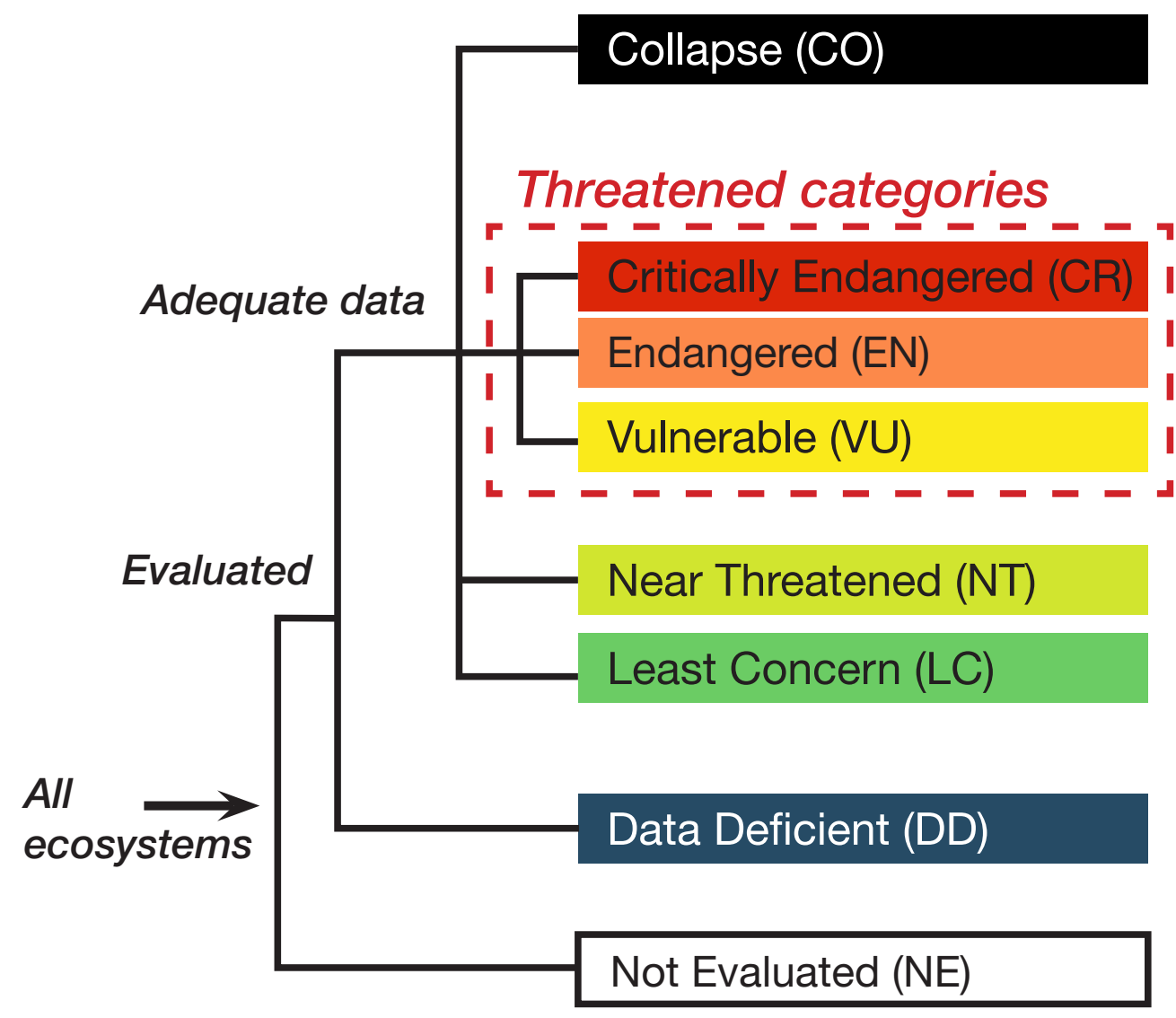

Figure 1. Structure of the IUCN Red List of Ecosystems categories

Ecosystems that are of Least Concern are likely to be well managed, and when a status of an ecosystem moves from more to less threatened categories (eg. CR to VU), then it is likely that management has improved its status.

\section{Box 1: Summary of the IUCN RLE Categories}

Collapsed (CO): An ecosystem is Collapsed when it is virtually certain that its defining biotic or abiotic features are lost, and the characteristic native biota are no longer sustained.

Critically Endangered (CR): An ecosystem is Critically Endangered when the evidence indicates that it meets any of the criteria $\mathrm{A}$ to $\mathrm{E}$ for $\mathrm{CR}$. It is then considered to be at an extremely high risk of collapse.

Endangered (EN): An ecosystem is Endangered when the evidence indicates that it meets any of the criteria $A$ to $E$ for EN, and is then considered to be at a very high risk of collapse.

Vulnerable (VU): An ecosystem is Vulnerable when the best available evidence indicates that it meets any of the criteria $\mathrm{A}$ to $\mathrm{E}$ for $\mathrm{VU}$, and is then considered to be at a high risk of collapse.

Near Threatened (NT): An ecosystem is Near Threatened when it has been evaluated against the criteria but does not qualify for CR, EN or VU, but it is close to qualifying for or is likely to qualify for a threatened category in the near future.

Least Concern (LC): An ecosystem is of Least Concern when it has been evaluated against the criteria and does not qualify for CR, EN, VU or NT. Widely distributed and relatively intact ecosystems are included.

Data Deficient (DD): An ecosystem is Data Deficient when there is inadequate information to make a direct, or indirect, assessment of its risk of collapse. DD is not a category of threat and does not imply any level of collapse risk. Listing ecosystems in this category indicates that their situation has been reviewed, but that more information is required to determine their risk status.

Not Evaluated (NE): An ecosystem is Not Evaluated when it is has not been assessed against any of the criteria. 


\section{LISTING CRITERIA AND THEIR APPLICATION}

\subsection{The Criteria and their application}

The RLE approach comprises five rule-based criteria (A-E, Annex 2) for assigning ecosystems to a risk category. Risks to ecosystems may be caused by a variety of threatening processes that are expressed through different symptoms of ecosystem collapse (Fig. 2). Each of the five RLE criteria addresses different groups of symptoms and identifies the corresponding means that link the symptoms to the risk that an ecosystem will collapse (i.e. lose its defining features). Two of the five criteria are based on spatial symptoms of ecosystem collapse: the rates of decline in distribution (A), and the degree to which the distribution is restricted (B). Two criteria are based on functional symptoms of ecosystem collapse: the rate and extent of environmental degradation $(\mathrm{C})$, and the rate and extent of disruption of biotic processes and interactions (D). The fifth criterion facilitates the integration of multiple threats and symptoms into a model to produce quantitative estimates of the risk of collapse (E). When applied according to the Guidelines, these criteria are a repeatable, globally consistent method for classifying the risk of ecosystem collapse.

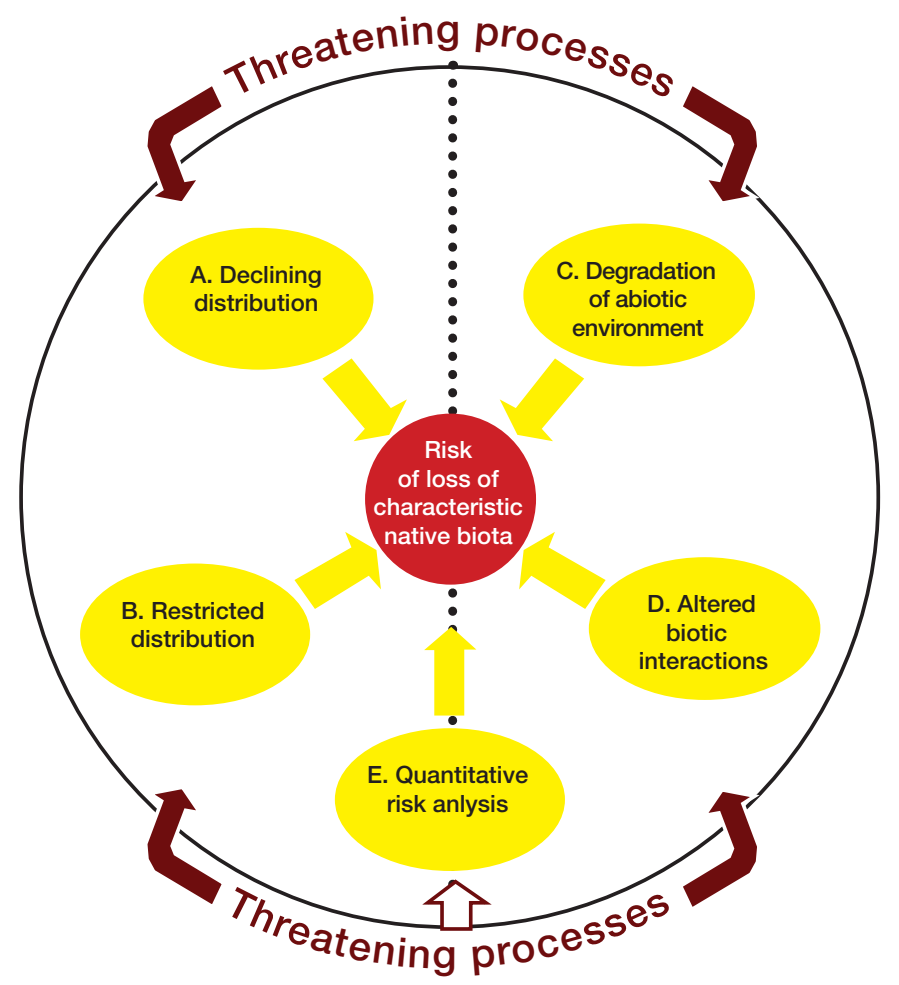

Figure 2. Mechanisms of ecosystem collapse and symptoms of collapse risk ${ }^{6}$

Criterion A. Reduction in geographic distribution?: A decline in geographic distribution influences its risk of collapse by (i) reducing the ability of an ecosystem to sustain its characteristic native biota; and (ii) predisposing it to additional threats. On-going declines in distribution lead to the loss of characteristic native biota occurs through a combination of reduced carrying capacity, reduced niche diversity, spatial separation of resources, and increased susceptibility to competition, predation and threats. The rate of decline in an ecosystem indicates its speed towards collapse (Box 2).

Criterion B. Restricted geographic distribution: The extent of geographic distribution of an ecosystem influences its risk of collapse when exposed to spatial threats, for example invasive species, pollution, and climate change. The primary role of criterion B is to identify ecosystems whose distribution is so spatially restricted (confined to a small area) that they are at risk of collapse from the chance occurrence of a single or few threatening events, for example invasive species or fire. Ecosystems that are widely distributed, existing across multiple independent patches are at lower risk from spatial threats.

$\overline{6}$ Keith, D. A., J. P. Rodríguez, K. M. Rodríguez-Clark, E. Nicholson, K. Aapala, A. Alonso, M. Asmüssen, S. Bachman, A. Basset, E. G.Barrow, J. S. Benson, M. J. Bishop, R. Bonifacio, T. M. Brooks, M. A. Burgman, P. Comer, F. A. Comín, F. Essl, D. Faber-Langendoen, P. G. Fairweather, R. J. Holdaway, M. Jennings, R. T. Kingsford, R. E. Lester, R. M. Nally, M. A. McCarthy, J. Moat, M. A. Oliveira-Miranda, P. Pisanu, B. Poulin, T. J. Regan, U. Riecken, M. D. Spalding and S. Zambrano-Martínez (2013) Scientific Foundations for an IUCN Red List of Ecosystems. PLoS ONE 8(5): e62111. http://www.plosone.org/article/info:doi/10.1371/journal.pone.0062111 The geographic distribution of an ecosystem type represents all spatial occurrences of an ecosystem type 


\section{Box 2. Distribution map of the Yellow Sea tidal flat ecosystem (Criterion A and B ${ }^{8}$ )}

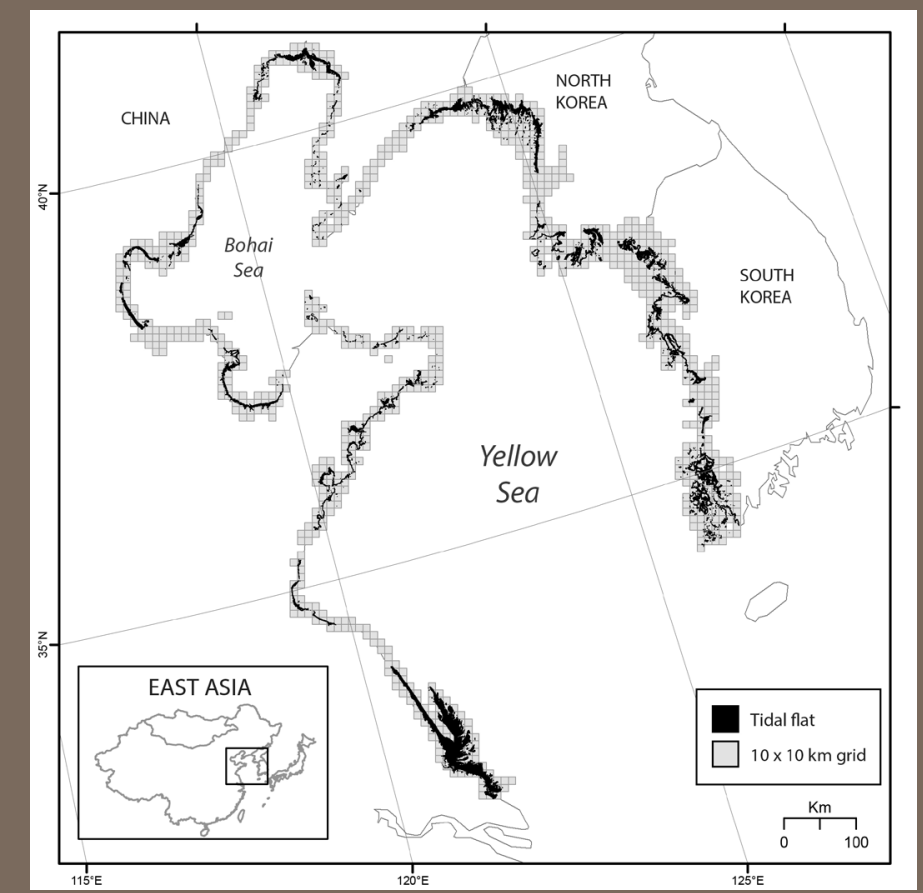

The distribution of the Yellow Sea tidal flat ecosystem was mapped by applying a peer-reviewed remote sensing classification method to Landsat Archive satellite imagery. The map has an overall accuracy of at least $94 \%$. Estimates of the area of the ecosystem type for criterion A are derived from the distribution of the ecosystem (black), whereas the area of occupancy is determined by counting the number of $10 \times 10 \mathrm{~km}$ cells in which $>1 \mathrm{~km}^{2}$ of the ecosystem type occurs (grey).

Criterion C. Environmental degradation: Abiotic degradation is the deterioration of the physical, non-living attributes that have a defining role in ecosystem-specific characteristics (e.g. specific ecological processes and/or the distribution of an ecosystem). This is one of the strengths and value-added of the RLE in being able to identify such threats. Abiotic degradation reduces the capacity of an ecosystem to sustain its biota and ecological processes, e.g. shifts in fire regimes, environmental flows, and climatic conditions (Box 3 ).

\section{Box 3. Assessing environmental degradation (Criterion $\mathbf{C}^{9}$ )}

Flooding is a key ecological process that sustains the Gonakier Forests of the Senegal River Floodplain in Senegal-Mauritania. As floods occur only during the wet season, the maximum annual river height was assumed to be indicative of the river's capacity to flood each year. River height data were available for 100 years from 1904 to 2003 . To assess criterion C, the mean annual maximum river height across four gauging stations was used as a proxy for environmental degradation. River flows declined sharply, reaching a minimum during the late 1970 s and 1980 s. Floods of $2,500 \mathrm{~m}^{3} / \mathrm{s}$, which are needed for floodplain inundation, would be very unlikely to occur based on river flows observed during 1986-1989. Extreme rates of tree mortality were observed between the mid-1970s and the mid-1980s, corresponding to the lowest maximum river heights $(473 \pm 27 \mathrm{~cm})$ observed during the 100 years of records.

Based on these observations, the collapse threshold was defined as the mean maximum river height for a 50 -year period falling below $450-500 \mathrm{~cm}$, causing extensive tree mortality. To calculate the relative severity of hydrological decline, the time series was divided into the reference period (19041953) and the present period (1954-2003). Since the collapse threshold is an interval, relative severity was estimated for the lower and upper bounds of the interval. Since hydrological decline affects the entire ecosystem, it was assumed that the extent of the threat was $>80 \%$, thus leading to the conclusion that the ecosystem is Vulnerable according Criterion C1 (degradation with relative severity $\geq 30 \%$ over an extent $\geq 80 \%$ in the last 50 years).

$8 \quad$ Murray N.J., Ma Z., and R.A. Fuller (2015): Tidal flats of the Yellow Sea: A review of ecosystem status and anthropogenic threats. Austral Ecol., 40.4 472-481

9 Keith, D. A., J. P. Rodríguez, K. M. Rodríguez-Clark, E. Nicholson, K. Aapala, A. Alonso, M. Asmüssen, S. Bachman, A. Basset, E. G.Barrow, J. S. Benson, M. J. Bishop, R. Bonifacio, T. M. Brooks, M. A. Burgman, P. Comer, F. A. Comín, F. Essl, D. Faber-Langendoen, P. G. Fairweather, R. J. Holdaway, M. Jennings, R. T. Kingsford, R. E. Lester, R. M. Nally, M. A. McCarthy, J. Moat, M. A. Oliveira-Miranda, P. Pisanu, B. Poulin, T. J. Regan, U. Riecken, M. D. Spalding and S. Zambrano-Martínez (2013) Scientific Foundations for an IUCN Red List of Ecosystems. PLoS ONE 8(5): e62111. http://www.plosone.org/article/info:doi/10.1371/journal.pone.0062111 
Criterion D. Disruption of biotic processes and interactions: Biodiversity loss reduces the capacity of ecosystems to capture resources, produce biomass, decompose organic matter and recycle carbon, water and nutrients. The diversity of organisms contributes to ecosystem functions. Disruptions to biotic and abiotic processes and interactions can cause collapse, regime shifts and re-organisation towards novel ecosystems (Box 4).

Criterion E. Quantitative risk analysis: This is an analysis that takes into account potential changes and identifies scenarios to help forecast possible outcomes for ecosystems over time to estimate the probability of ecosystem collapse. This is done through a quantitative model of ecosystem functions to: a) incorporate multiple threats and interactions; b) provide a synthetic view of processes captured in other criteria; and c) forecast ecosystem status under different scenarios (Fig. 3).

\section{Box 4. Assessing disruption of biotic processes (criterion $D^{10}$ )}

Alaskan Giant Kelp Forests are diverse and characterised by species of brown algae. These create a complex and dynamic layered forest architecture up to $15 \mathrm{~m}$ tall that provides substrate, shelter and foraging resources for a diverse fauna of invertebrate herbivores and pelagic vertebrate predators. The most serious disruption to biotic interactions involves sea otters, their predators (killer whales) and their prey (urchins, which consume kelp). Densities of kelp are inversely related to densities of urchins, and that shifts between forests and urchin barren areas are related to the abundance of otters.

Survey data for kelp densities were available between 1987 and 2000 from seven islands in the area. It was assumed that the seven islands, scattered across the Aleutian chain, were representative of the full distribution of the ecosystem. Ecosystem collapse occurs when kelp density is close to zero. Rates of change in kelp density were calculated for each island. A weighted average across all sites indicated that kelp densities declined on average by $49.2 \%$ between 1987 and 2000 . Allowing for some decline prior to 1987 or after 2000 suggests that the decline in kelp density over the past 50 years was at least $50 \%$ across the full ecosystem extent. Aerial survey data for sea otters were available for 55 islands along the Aleutian chain between 1959 and 2000. Ecosystem collapse occurs when otter populations reach zero across all sites. The total population was estimated to be $55,000-74,000$ prior to declines in the mid-1980s. By 2000 there were a total of 3,924-13,580 animals based on extrapolation from the aerial survey. Evidence from trends in kelp density and sea otter sightings suggest a decline in biotic function of $50-95 \%$, and a relative severity across $100 \%$ of the ecosystem extent. The most likely status of the ecosystem under criterion D1 is Endangered, although a status of Critically Endangered is possible.

\subsection{Assessment approach}

The RLE uses five criteria to assess risks to ecosystems (Fig. 2), which correspond to different symptoms of ecosystem decline. An ecosystem type under assessment must be evaluated using all of the criteria for which data are available (Annex 1). The overall risk status of the ecosystem type is assigned as the highest category of risk obtained through any criterion. The criteria assess declines over four specified time frames: the recent past, the present, the future, and the historical past. The 'recent past' time frame encompasses the past 50 years, which is sufficiently recent to capture current trends, but long enough to distinguish change from natural variability. The RLE assumes that declines over this time frame are indicative of future risk irrespective of cause.

Assessment of future declines requires predictions of changes over the next 50 years or any 50 -year period including the present and future. Past declines provide a basis for such predictions, but other information may support predictions and inferences about rates of future decline (e.g. climate change projections). Such predictions require valid assumptions about the pattern of future change (e.g. increasing, constant, or decreasing). Assessments of historical declines are essential for ecosystems containing biota with long generation lengths and slow population turnovers. They are also essential for foundation species with short generation lengths which may have suffered extensive historical declines. Historical declines are assessed relative to ecosystem status during the pre-industrial period, which corresponds to the year $~ 1750$ in many parts of the world.

10 Estes J.A., Tinker M., and J.L. Bodkin (2010): Using ecological function to develop recovery criteria for depleted species: sea otters and kelp forests in the Aleutian archipelago. Conservation Biology 24, 852-860 


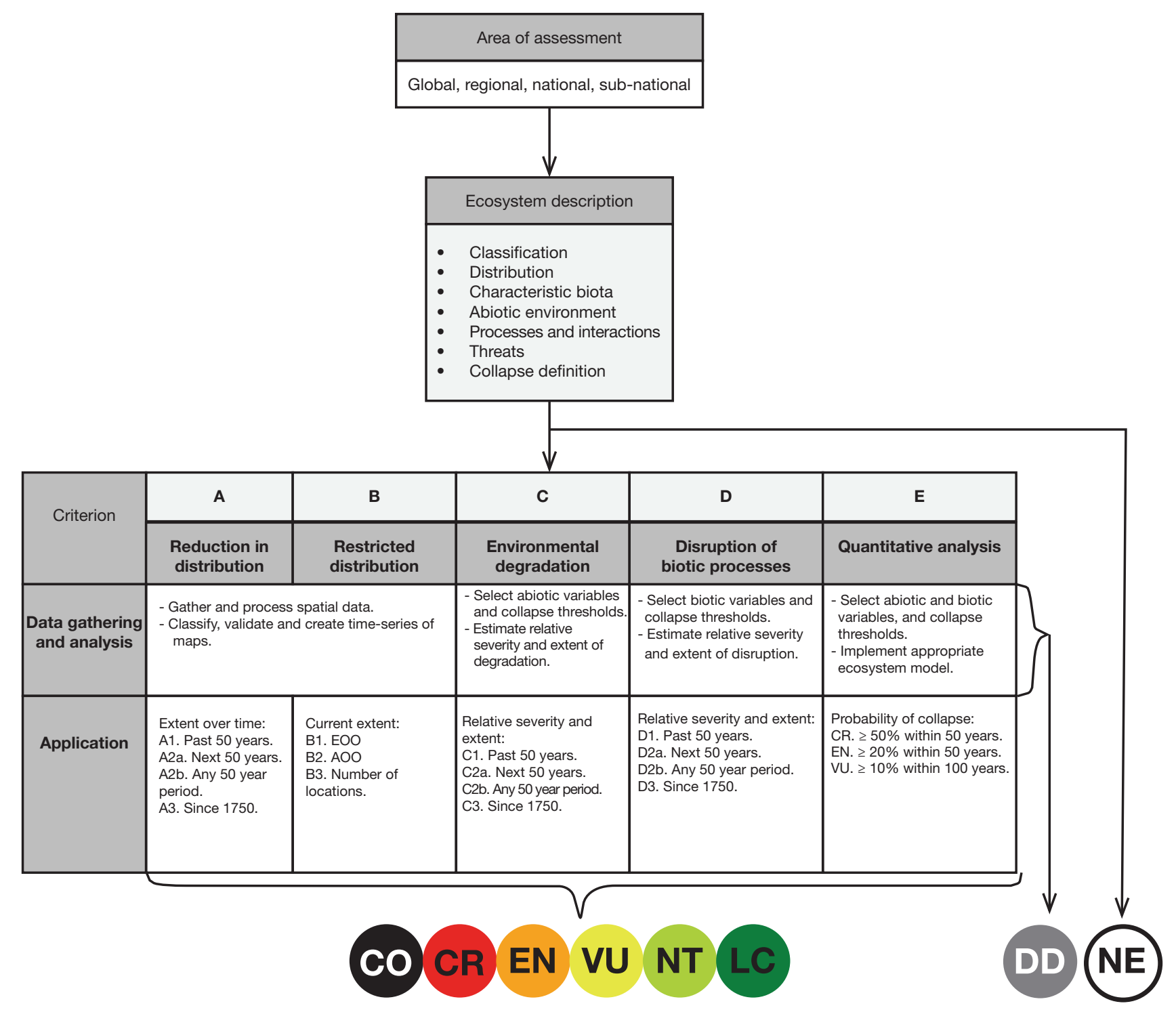

Figure 3. Process for assessing the risk of collapse of an ecosystem type ${ }^{11}$.

The categories of risk are delimited by thresholds, and are based on theoretical and practical considerations. The purpose of these thresholds is to rank ecosystems in informative categories of risk, rather than estimate precise probabilities of collapse. Consequently, for Criteria A, C, and D, threshold values were set at relatively even intervals for current and future declines in ecosystem distribution or function (Vulnerable: 30\%, Endangered: 50\%, Critically Endangered: $80 \%$. Fig 3 summarizes this process).

Achieving a robust and repeatable assessment for an ecosystem requires data from varied sources. The categories and criteria are designed to allow the inclusion of data from a range of sources. It is the responsibility of the assessor to evaluate whether data quantity and quality are sufficient to support the outcome of an assessment. Key principles include:

1. Evaluate the type, amount, quality, and consistency of evidence;

2. Evaluate the degree of agreement among different sources of evidence;

3. Provide a traceable account describing the evaluation of evidence and agreement;

4. Evaluate the likelihood of alternative categories as outcomes of an assessment; and

5. Communicate the uncertainty in the outcomes of an assessment by reporting the most likely category and as well as categories that represent likely upper and lower bounds of the assessment outcome.

11 Bland, L.M., Keith, D.A., Miller, R.M., Murray, N.J. and Rodríguez, J.P. (eds.) (2016). Guidelines for the application of IUCN Red List of Ecosystems Categories and Criteria, Version 1.0. Gland, Switzerland: IUCN. ix + 94pp 


\section{SCIENTIFIC BASIS FOR THE RLE}

\subsection{Ecosystem types: the units and scope of assessment}

The RLE approach is a robust and generic risk assessment framework that can be applied, in a repeatable manner to support planning decisions for conservation and resource use: i) individual ecosystem types that are a particular focus of management; ii) comprehensive classifications of ecosystems across a geographic area of interest (e.g. a country); iii) a comprehensive global ecosystem classification. It has the flexibility to assess risks to ecosystems that vary greatly in biological and environmental characteristics, scales of organisation, and amounts of available data. The clear definition and description of the ecosystems is an essential first step towards an RLE assessment.

Ecosystem types are the units of assessment, and are complexes of organisms and their associated physical environment within a specified area. They have four essential elements: a biotic complex, an abiotic environment, the interactions within and between them, and a physical space in which these operate. Many related concepts that have evolved at different scales (subnational to national) may be treated as ecosystem types for the purposes of Red List assessments at particular scales (habitat types, ecosystems, ecological communities, biomes). These are distinguished from ecoregions or bioregions, which represent contiguous bioregiographic regions that may include groups of co-occurring, but contrasting ecosystem types. For example, an ecoregion make include several forest, wetland and shrubland ecosystem types.

The RLE Categories and Criteria may be applied to: i) individual ecosystem types that are a particular focus of management; ii) comprehensive classifications of ecosystems across a geographic area of interest (e.g. a country); iii) a comprehensive global ecosystem classification. Standalone assessments of single ecosystems have proven to be useful tools for monitoring and management.

The development of a global ecosystem conceptual framework typology to describe and classify ecosystems is currently underway, and is guided by recent research on classifications of terrestrial vegetation and marine environments. In the interim, the IUCN Habitats Classification Scheme provides a useful comparative framework for assessments of contrasting ecosystem types.

The concept of characteristic native biota is central to the RLE. Characteristic native biota include the genes, populations, species, assemblages of species and their interactions that: (i) distinguish different ecosystems; and (ii) have a central role in ecosystem dynamics, structure, and functions.

The RLE risk assessment approach is designed to be flexible for application at multiple spatial scales (local, national, regional, global), and with a range of data sources. But there are practical limits to the spatial, temporal and thematic scales of units that can be assessed, and within these limits the assessment outcomes are sensitive to scale. Assessments of ecosystems that are, for example, too broadly or narrowly defined, could lead to incomparable assessments across scales, or invalid assessment outcomes. Assessments should follow the Guidelines for the application of IUCN Red List of Ecosystems Categories and Criteria to ensure comparability of across different scales and areas.

\subsection{Ecosystem collapse}

To achieve a robust application of RLE, an assessor must analyse diverse causes, mechanisms and pathways of ecosystem decline within the generic risk assessment framework. To estimate risk-the probability of an adverse outcome over a specified time frame ${ }^{12}-$ it is necessary to define the adverse outcome as an endpoint of ecosystem decline: the point at which an ecosystem is considered collapsed and has undergone transformation into a different ecosystem. The endpoint or "threshold of collapse" must be defined quantitatively using one or more suitable proxy variables that faithfully represent the state of the ecosystem. The endpoint must be sufficiently discrete to permit an assessment, but assessors can incorporate uncertainty by expressing the endpoint as a range of plausible proxy values. For example, the threshold of collapse for an alpine ecosystem type may be defined as when snow cover persists for less than 2-6 weeks of the year for more than three years out of five. 


\section{Box 5. Ecosystem collapse in the Aral Sea ${ }^{13}$}

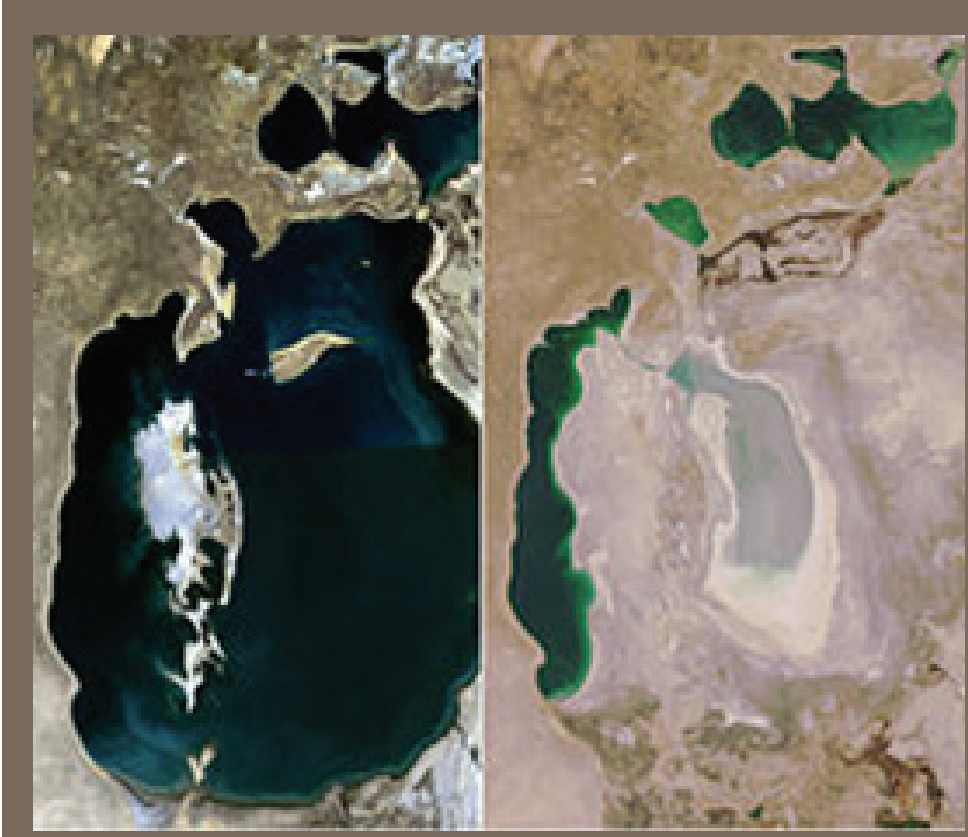

The Aral Sea - the world's fourth largest continental water body - is fed by the Syr Dar'ya and Amu Dar'ya rivers. Its characteristic native biota includes freshwater fish (20 species), a unique invertebrate fauna (>150 species) and shoreline reed beds, which provide habitat for water birds, including migratory species. The sea was stable from 19111960. But increases in water extraction for irrigated agriculture lead to the shrinkage and salinization of the sea. By 2005 , only 28 aquatic species (including fish and invertebrates) were recorded, reed beds had dried and disappeared, the sea had contracted to a fraction of its former volume and surface area, while salinity had increased tenfold. As a result the Aral Sea had undergone a transformation of identity, and been replaced by novel ecosystems (saline lakes and desert

plains). Collapse occurred before the volume and surface area of standing water declined to zero between 1976 and 1989 when most biota disappeared.

Fish species richness and abundance may be the most important variable that define the identity of the Aral Sea ecosystem. Sea volume may be a reasonable abiotic proxy, because volume is functionally linked with salinity. Collapse of the Aral Sea ecosystem may or may not be reversible. While it may be possible to restore the hydrological regime over a part of the former sea, some components of the characteristic biota are apparently extinct, which would prevent the reconstruction of the pre-collapse ecosystem. (Image: @ NASA)

An ecosystem is considered Collapsed "when it is virtually certain that it's defining biotic or abiotic features are lost, and the characteristic native biota ${ }^{14}$ are no longer sustained". Collapse may occur when most of the characteristic native biota are lost from the system, or when ecological function is severely impacted (e.g. through the loss of key species interactions or ecological cycles). Collapse is a transformation of identity, a loss of defining features, and/or replacement by a different, novel ecosystem. This can be illustrated by examples such as the Aral Sea (Box 5).

Unlike species, ecosystems do not disappear. For ecosystems, there is no equivalent to extinction-, rather they transform into novel ecosystems with different characteristic biota and mechanisms of organisation. The novel systems may retain some characteristic biota of the collapsed systems that they replace, but the abundance of those species, their interactions or ecological functions are altered beyond scientifically defined thresholds. Ecosystem collapse may in theory be reversible-given a long time frame, or through the reintroduction of native species and/or the restoration of ecosystem function. However, in most cases this is unfeasible or too expensive.

13 Keith, D. A., J. P. Rodríguez, K. M. Rodríguez-Clark, E. Nicholson, K. Aapala, A. Alonso, M. Asmüssen, S. Bachman, A. Basset, E. G.Barrow, J. S. Benson, M. J. Bishop, R. Bonifacio, T. M. Brooks, M. A. Burgman, P. Comer, F. A. Comín, F. Essl, D. Faber-Langendoen, P. G. Fairweather, R. J. Holdaway, M. Jennings, R. T. Kingsford, R. E. Lester, R. M. Nally, M. A. McCarthy, J. Moat, M. A. Oliveira-Miranda, P. Pisanu, B. Poulin, T. J. Regan, U. Riecken, M. D. Spalding and S. Zambrano-Martínez (2013) Scientific Foundations for an IUCN Red List of Ecosystems. PLoS ONE 8(5): e62111. http://www.plosone.org/article/info:doi/10.1371/journal.pone.0062111 Biological features that define the identity of an ecosystem type and distinguish it from other ecosystem types and/or drive ecosystem dynamics and function, e.g. ecological processes, ecosystem engineers, trophic or structural dominants, functionally unique elements, species interactions 


\section{ASSESSMENT PROCESS}

\subsection{Describing the unit of assessment}

To ensure repeatable RLE application, a detailed description of the ecosystem is essential. This must provide information on its classification and distribution. It also needs to clearly describe the four elements that define the ecosystem (characteristic native biota; abiotic environment; key processes and interactions; and spatial distribution), and describe the threats and collapsed states.

Descriptions should identify the abiotic features that influence the distribution or function of an ecosystem type, define its natural range of variability, sustain its native biota, and differentiate it from other systems. For terrestrial ecosystems, important abiotic features include substrates, soils and landforms, as well as climatic variables. For freshwater and marine systems, they may include key aspects of water and light regimes, tides, currents, climatic factors, and physical and chemical properties of the water column. Ecosystem types should be cross-referenced to relevant ecosystem classifications, including vegetation classifications for terrestrial systems, ecoregional classifications, and the IUCN Habitats Classification Scheme. The spatial distribution of the ecosystems are best represented by maps or inventories of locations.

To better understand the processes at play in any ecosystem unit, a diagram reflecting the dynamics between key ecosystem components and the threats they face is required as an early step of the assessment. This conceptual diagram or model serves four purposes: (1) it compels assessors to think through and clarify their assumptions and understanding of ecosystem processes; (2) provides a basis for conducting the risk assessment, by informing the selection of relevant variables for assessing Criteria C and D; (3) is a communication tool that effectively summarises key features of an ecosystem type for risk managers, conservation practitioners, peer reviewers and the wider community; and (4) is useful for underpinning the development of a quantitative model for Criterion E (Fig.4).

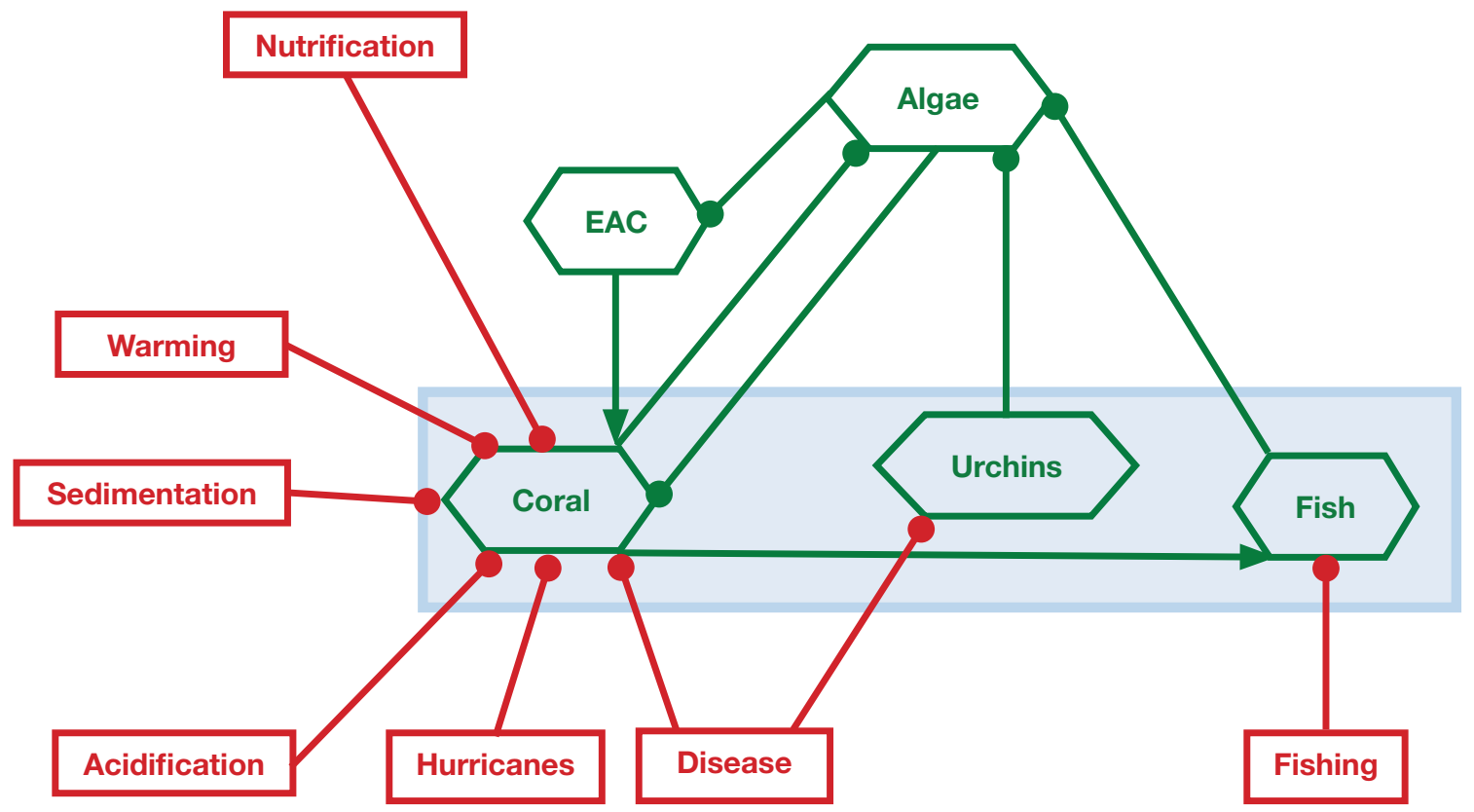

Figure 4. An Example of a conceptual model of the risk assessment of the Meso-American Reef. (EAC: Epilithic Algal Communities)

Accompanying the description of an ecosystem should be a review of threats, which requires: (i) a brief description and explanation of the major threats; and (ii) identification of threats with reference to the IUCN Threats Classification Scheme. The description provides a brief explanation of the major threats (past, present and future), the drivers of those threats, and the resultant stresses on the ecosystem. The spatial distribution of threats should also be described. 


\subsection{Sub-global assessments}

The RLE assessments may be undertaken at different geographic scales. Global assessments consider all occurrences of an ecosystem type throughout the world. This is essential for the set of broadly defined ecosystems that will form the global RLE, and for informing international biodiversity targets and global conservation strategies. Sub-global assessments are defined by political (continental, national or state/subnational assessments), or eco-regional boundaries (e.g. ocean basins or river catchments). Sub-global lists of ecosystems already exist, for example Germany, Finland, Venezuela, Austria, Norway, South Africa, New Zealand, El Salvador, Costa Rica and Colombia.

Sub-global assessments, which consider all ecosystems within a geographic domain (such as a country), may be based on national or regional classifications, providing the units of assessment conform to the definition of ecosystems. These suitability of these units should be adequately described and crossreferenced (or nested where possible) to national, regional and global classification systems.

For sub-global assessments, it is best to assess ecosystem types defined at a finer resolution than for global assessments. Sub-global assessments will usually require finer detail, supported by sufficient local data, to support conservation, land and water use decision-making, and can more easily be based on pre-existing or updated national classifications. The same ecosystem type may, however, be assigned to different risk categories in sub-global and global assessments due to the nature and scale of the assessment. Differences in status depend on the distribution of threats across the range of the ecosystem in relation to the boundaries of the assessment area. But some general rules apply for sub-global assessments: a). A comprehensive description of the ecosystem is still required. The area of assessment (e.g. political boundaries) must be clearly defined and supported with maps; and b). No modifications of the categories or criteria are allowed when making sub-global assessments of ecosystems. Therefore, all thresholds, time frames, definitions and data requirements remain unchanged for sub-global applications of the RLE.

\subsection{Documenting the assessment}

All assessments must be accompanied by documentation and supporting information, undergo peer review, and be made freely available when completed (see www.iucnrle.org/). All required fields in the online RLE database should be completed, and the documentation includes the following sections:

1. Summary: An abstract ( 200 words) that describes the assessment, including its area, the focal ecosystem type and its defining features, threats and the assessment outcome;

2. Ecosystem description: A complete description of the ecosystem with spatial data (examples available on website);

3. Risk assessment: Application and outcome of each criterion should include a discussion of assumptions, limitations or further data required; and

4. References: A complete reference list showing the sources of information used. 


\section{PEER REVIEW AND PUBLICATION}

The IUCN RLE Committee for Scientific Standards (CSS) coordinates independent peer review of risk assessments for the global RLE. Reviews of sub-global assessments will be the responsibility of project managers, though they are encouraged to seek advice from the CSS. Assessments will be reviewed by at least two experts: one with expertise in the ecology of the ecosystem type under assessment and another familiar with the RLE. The review criteria include whether:

1. The ecosystem type is consistent with the definition of an ecosystem, and is valid for assessment using the RLE criteria;

2. Documentation includes an adequate description of the ecosystem type. This includes links to relevant classifications, key ecological processes and threats, a graphical conceptual model, and a quantitative evaluation of each criterion for which data exist;

3. All accessible data and information relevant to the RLE assessment of the ecosystem type have been addressed;

4. The quality of underlying data has been evaluated and found to be adequate;

5. Definitions and concepts in the guidelines have been correctly interpreted and applied;

6. Methods were correctly applied, and whether other methods are more suitable;

7. Estimates of variables for past, present, future, and collapsed states are complete and supported by evidence;

8. Inferences related to the RLE criteria are justified and transparently communicated; and

9. Whether uncertainties have been adequately incorporated in the assessment.

\section{POLICY AND GOVERNANCE BASIS}

The adoption of Resolution 4.020 on Quantitative Thresholds for Categories and Criteria of Threatened Ecosystems (Fourth World Conservation Congress, Barcelona, 2008) called for the development of formal categories and criteria. The Resolution requested IUCN to "initiate a consultation process for the development, implementation and monitoring of a global standard for the assessment of ecosystem status, applicable at local, regional and global levels." Between 2008 and 2012, the RLE Thematic Group of the Commission on Ecosystem Management (CEM) produced a draft set of criteria. Since then, they were tested across a suite of ecosystem types by external partners in collaboration with the IUCN Global Ecosystem Management Programme (GEMP). These partners include national governments and agencies from a number of countries, researchers in many universities, and civil society organizations.

The Fifth World Conservation Congress (Jeju, 2012) adopted Resolution 5.055 on the Consolidation of the IUCN Red List of Ecosystems, which acknowledged the progress of the RLE development and requested the IUCN Council to "take the necessary steps for formal approval of the categories and criteria as an official IUCN data analysis protocol for use by the Members and any other stakeholder interested in ecosystem risk assessment". Council examined the updated version of the IUCN Red List of Ecosystems Categories and Criteria, and on 21 May 2014 adopted them as the official IUCN global standard for assessing the risks to ecosystems.

The RLE is jointly coordinated by IUCN CEM and GEMP. It is governed by two interacting committees with specific functions: (i) the Steering Committee, and (ii) a Committee for Scientific Standards (CSS). It is supported by the RLE Thematic Group of CEM, which is a group of volunteer experts that support the RLE objectives - most of whom are located in Caracas (Venezuela), Sydney and Melbourne (Australia). The RLE Secretariat Unit-based in Cambridge, United Kingdom; Gland, Switzerland; and Nairobi, Kenyaadministers the RLE, and ensures global coordination of the experts involved in research, implementation and peer review.

\section{End Note}

We hope that this introduction to the RLE will stimulate interest for further information, and assist you in deciding whether and how to carry out an RLE assessment (ecosystem level, sub-national, national or regional). Should you wish to carry out an RLE assessment, please refer to Version 1 of the Guidelines. Annex 1 provides a number of useful references to further explore the RLE. There is a lot of information on the RLE web site (www.iucnrle.org) and you can contact the RLE team through the web site ${ }^{15}$. 


\section{Annex 1: Key references for further information}

The following documents are available on www.iucnrle.org together with many publications

Bland, L.M., Keith, D.A., Miller, R.M., Murray, N.J. and Rodríguez, J.P. (eds.) (2016). Guidelines for the application of IUCN Red List of Ecosystems Categories and Criteria, Version 1.0. Gland, Switzerland: IUCN. ix + 94pp. [doi: 10.2305/IUCN.CH.2016.RLE.1.en].

Keith, D.A., Rodríguez, J.P., Brooks, T.M., Burgman, M.A., Barrow, E.G., Bland, L., Comer, P.J., Franklin, J., Link, J., McCarthy, M.A., Miller, R.M., Murray, N.J., Nel, J., Nicholson, E., Oliveira-Miranda, M.A., Regan, T.J., Rodríguez-Clark, K.M., Rouget, M. and Spalding, M.D. (2015). The IUCN Red List of Ecosystems: motivations, challenges and applications. Conservation Letters [doi: 10.1111/ conl.12167].

Rodríguez, J.P., Keith, D.A., Rodríguez-Clark, K.M., Murray, N.J., Nicholson, E., Regan, T.J., Miller, R.M., Barrow, E.G., Bland, L.M., Boe, K., Brooks, T.M., Oliveira-Miranda, M.A., Spalding, M. and Wit, P. (2015) A practical guide to the application of the IUCN Red List of Ecosystems criteria. Phil. Trans. R. Soc. B 370: 20140003. [doi: 10.1098/rstb.2014.0003].

Keith, D.A. (2015) Assessing and managing risks to ecosystem biodiversity. Austral Ecology 40(4): 337-346. [doi:10.1111/aec.12249].

Keith, D. A., J. P. Rodríguez, K. M. Rodríguez-Clark, E. Nicholson, K. Aapala, A. Alonso, M. Asmüssen, S. Bachman, A. Basset, E. G. Barrow, J. S. Benson, M. J. Bishop, R. Bonifacio, T. M. Brooks, M. A. Burgman, P. Comer, F. A. Comín, F. Essl, D. Faber-Langendoen, P. G. Fairweather, R. J. Holdaway, M. Jennings, R. T. Kingsford, R. E. Lester, R. M. Nally, M. A. McCarthy, J. Moat, M. A. Oliveira-Miranda, P. Pisanu, B. Poulin, T. J. Regan, U. Riecken, M. D. Spalding and S. Zambrano-Martínez (2013) Scientific Foundations for an IUCN Red List of Ecosystems. PLoS ONE 8(5): e62111. http://www. plosone.org/article/info:doi/10.1371/journal.pone.0062111.

Rodríguez J.P, Rodríguez-Clark K.M., Keith D.A., Barrow E.G., Comer P. and Oliveira-Miranda M.A. (2012) From Alaska to Patagonia: the IUCN Red List of continental ecosystems of the Americas. Oryx 46(02): 170-171.

Rodríguez J.P., Rodríguez-Clark K.M., Keith D.A., Barrow E.G., Benson J., Nicholson E. and Wit P. (2012) IUCN Red List of Ecosystems. S.A.P.I.EN.S., 5.2. 


\section{Annex 2. IUCN Red List of Ecosystems Criteria, Version 2.116}

Criterion A. Reduction in geographic distribution over ANY of the following time periods:

A2b. any 50 year

eriod including the past, $\quad$ A3. since 1750 present and future

\begin{tabular}{|c|c|ccc|}
\hline CR & $\geq 80 \%$ & $\geq 80 \%$ & $\geq 80 \%$ & $\geq 90 \%$ \\
\hline EN & $\geq 50 \%$ & $\geq 50 \%$ & $\geq 50 \%$ & $\geq 70 \%$ \\
\hline VU & $\geq 30 \%$ & $\geq 30 \%$ & $\geq 30 \%$ & $\geq 50 \%$ \\
\hline
\end{tabular}

Criterion B. Restricted geographic distribution indicated by ANY OF B1, B2 or B3:

B1. Extent of a minimum convex polygon enclosing all occurrences (extent of occurrence, EOO) is no larger than:

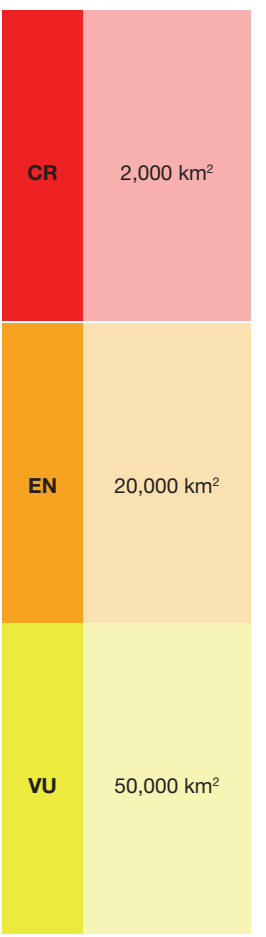

(a) An observed or inferred continuing decline in ANY OF:

i. a measure of spatial extent appropriate to the ecosystem; OR

AND at ii. a measure of environmental quality appropriate to characteristic biota of the ecost one of ecostem; OR

the iii. a measure of disruption to biotic interactions appropriate to the characteristic following biota of the ecosystem.

(a-c): (b) Observed or inferred threatening processes that are likely to cause continuing declines in geographic distribution, environmental quality or biotic interactions within the next 20 years.

(c) Ecosystem exists at 1 location

(a) An observed or inferred continuing decline in ANY OF

i. a measure of spatial extent appropriate to the ecosystem; OR

ii. a measure of environmental quality appropriate to characteristic biota of the ecosystem; OR

AND one of

the iii. a measure of disruption to biotic interactions appropriate to the characteristic following biota of the ecosystem.

(a-c):

(b) Observed or inferred threatening processes that are likely to cause continuing declines in geographic distribution, environmental quality or biotic interactions within the next 20 years.

(c) Ecosystem exists at $\leqq 5$ locations

(a) An observed or inferred continuing decline in ANY OF

i. a measure of spatial extent appropriate to the ecosystem; OR

ii. a measure of environmental quality appropriate to characteristic biota of the ecosystem; OR

AND at

the

iii. a measure of disruption to biotic interactions appropriate to the characteristic biota of the ecosystem

following
(a-c):

(b) Observed or inferred threatening processes that are likely to cause continuing declines in geographic distribution, environmental quality or biotic interactions within the next 20 years.

(c) Ecosystem exists at $\leqq 10$ locations

B2. The number of $10 \times 10 \mathrm{~km}$ grid cells occupied (area of occupancy, AOO) is no more than:

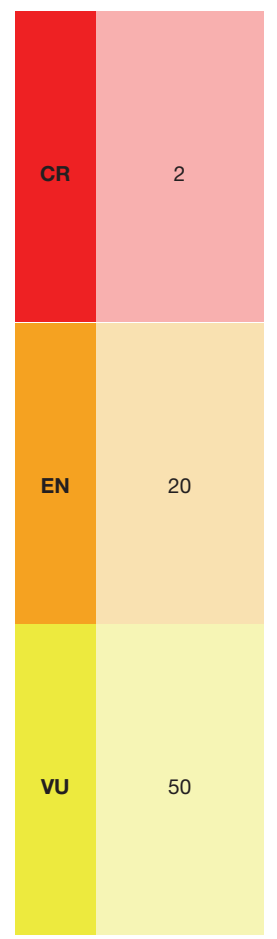

(a) An observed or inferred continuing decline in ANY OF:

i. a measure of spatial extent appropriate to the ecosystem; OR

AND at a measure of environmental quality appropriate to characteristic biota of the ecosystem; OR

ast one of

the

iii. a measure of disruption to biotic interactions appropriate to the characteristic biota of the ecosystem.

(a-c): (b) Observed or inferred threatening processes that are likely to cause continuing

declines in geographic distribution, environmental quality or biotic interactions within the next 20 years.

(c) Ecosystem exists at 1 location

(a) An observed or inferred continuing decline in ANY OF

i. a measure of spatial extent appropriate to the ecosystem; OR

ii. a measure of environmental quality appropriate to characteristic biota of the ecosystem; OR

AND at

least one of

the

following

iii. a measure of disruption to biotic interactions appropriate to the characteristic biota of the ecosystem.

$(\mathrm{a}-\mathrm{c})$ :

(b) Observed or inferred threatening processes that are likely to cause continuing declines in geographic distribution, environmental quality or biotic interactions within the next 20 years.

(c) Ecosystem exists at $\leqq 5$ locations

(a) An observed or inferred continuing decline in ANY OF

i. a measure of spatial extent appropriate to the ecosystem; OR

ii. a measure of environmental quality appropriate to characteristic biota of the ecosystem; OR

iii. a measure of disruption to biotic interactions appropriate to the characteristic biota of the ecosystem

(b) Observed or inferred threatening processes that are likely to cause continuing declines in geographic distribution, environmental quality or biotic interactions within the next 20 years.

(c) Ecosystem exists at $\leqq 10$ locations

16 Bland, L.M., Keith, D.A., Miller, R.M., Murray, N.J. and Rodríguez, J.P. (eds.) (2016). Guidelines for the application of IUCN Red List of Ecosystems Categories and Criteria, Version 1.0. Gland, Switzerland: IUCN. ix + 94pp 
B3. The number of locations is: Very small (generally fewer than 5) AND prone to the effects of human activities or stochastic events within a very short
time period in an uncertain future, and thus capable of Collapse or becoming Critically Endangered within a very short time period ( $\mathrm{B} 3$ can only lead to a listing as VU).

Criterion C. Environmental degradation over ANY of the following time periods:

\begin{tabular}{|c|c|c|c|c|}
\hline \multirow{5}{*}{$\begin{array}{l}\text { C1. The past } 50 \text { years, based on change in an abiotic variable affecting } \\
\text { a fraction of the extent of the ecosystem and with relative severity, as } \\
\text { indicated by the following table: }\end{array}$} & \multirow{3}{*}{$\begin{array}{l}\text { Extent }(\%) \\
\quad \geq 80\end{array}$} & \multicolumn{3}{|c|}{ Relative severity (\%) } \\
\hline & & $\geq 80$ & $\geq 50$ & $\geq 30$ \\
\hline & & CR & EN & vu \\
\hline & $\geq 50$ & EN & Vu & \\
\hline & $\geq 30$ & vu & & \\
\hline \multirow{3}{*}{$\begin{array}{l}\text { C2a. The next } 50 \text { years, based on change in an abiotic variable affecting } \\
\text { a fraction of the extent of the ecosystem and with relative severity, as } \\
\text { indicated by the following table; OR }\end{array}$} & & \multicolumn{3}{|c|}{ Relative severity (\%) } \\
\hline & Extent (\%) & $\geq 80$ & $\geq 50$ & $\geq 30$ \\
\hline & $\geq 80$ & CR & EN & vu \\
\hline \multirow{2}{*}{$\begin{array}{l}\text { C2b. Any 50-year period including the past, present and future, based } \\
\text { on change in an abiotic variable affecting a fraction of the extent of the } \\
\text { ecosystem and with relative severity, as indicated by the following table: }\end{array}$} & $\geq 50$ & EN & VU & \\
\hline & $\geq 30$ & Vu & & \\
\hline \multirow{5}{*}{$\begin{array}{l}\text { C3. Since } 1750 \text {, based on change in an abiotic variable affecting a } \\
\text { fraction of the extent of the ecosystem and with relative severity, as } \\
\text { indicated by the following table: }\end{array}$} & & \multicolumn{3}{|c|}{ Relative severity (\%) } \\
\hline & Extent (\%) & $\geq 90$ & $\geq 70$ & $\geq 50$ \\
\hline & $\geq 90$ & CR & EN & VU \\
\hline & $\geq 70$ & EN & Vu & \\
\hline & $\geq 50$ & VU & & \\
\hline
\end{tabular}

Criterion D. Disruption of biotic processes or interactions over ANY of the following time periods:

\begin{tabular}{|c|c|c|c|c|}
\hline \multirow{5}{*}{$\begin{array}{l}\text { D1. The past } 50 \text { years, based on change in a biotic variable affecting a } \\
\text { fraction of the extent of the ecosystem and with relative severity, as } \\
\text { indicated by the following table: }\end{array}$} & \multirow{3}{*}{$\begin{array}{l}\text { Extent }(\%) \\
\quad \geq 80\end{array}$} & \multicolumn{3}{|c|}{ Relative severity (\%) } \\
\hline & & $\geq 80$ & $\geq 50$ & $\geq 30$ \\
\hline & & CR & EN & vu \\
\hline & $\geq 50$ & EN & vu & \\
\hline & $\geq 30$ & Vu & & \\
\hline \multirow{5}{*}{$\begin{array}{l}\text { D2a. The next } 50 \text { years, based on change in a biotic variable affecting a } \\
\text { fraction of the extent of the ecosystem and with relative severity, as } \\
\text { indicated by the following table; OR } \\
\text { D2b. Any } 50 \text {-year period including the past, present and future, based } \\
\text { on change in a biotic variable affecting a fraction of the extent of the } \\
\text { ecosystem and with relative severity, as indicated by the following table: }\end{array}$} & & \multicolumn{3}{|c|}{ Relative severity (\%) } \\
\hline & Extent (\%) & $\geq 80$ & $\geq 50$ & $\geq 30$ \\
\hline & $\geq 80$ & CR & EN & Vu \\
\hline & $\geq 50$ & EN & vU & \\
\hline & $\geq 30$ & Vu & & \\
\hline \multirow{5}{*}{$\begin{array}{l}\text { D3. Since } 1750 \text {, based on change in a biotic variable affecting a } \\
\text { fraction of the extent of the ecosystem and with relative severity, as } \\
\text { indicated by the following table: }\end{array}$} & & \multicolumn{3}{|c|}{ Relative severity (\%) } \\
\hline & Extent (\%) & $\geq 90$ & $\geq 70$ & $\geq 50$ \\
\hline & $\geq 90$ & CR & EN & Vu \\
\hline & $\geq 70$ & EN & vU & \\
\hline & $\geq 50$ & VU & & \\
\hline
\end{tabular}

Criterion E. Quantitative analysis that estimates the probability of ecosystem collapse to be:

\begin{tabular}{|l|l|}
\hline CR & $\geq 50 \%$ within 50 years \\
\hline EN & $\geq 20 \%$ within 50 years \\
\hline VU & $\geq 10 \%$ within 50 years \\
\hline
\end{tabular}





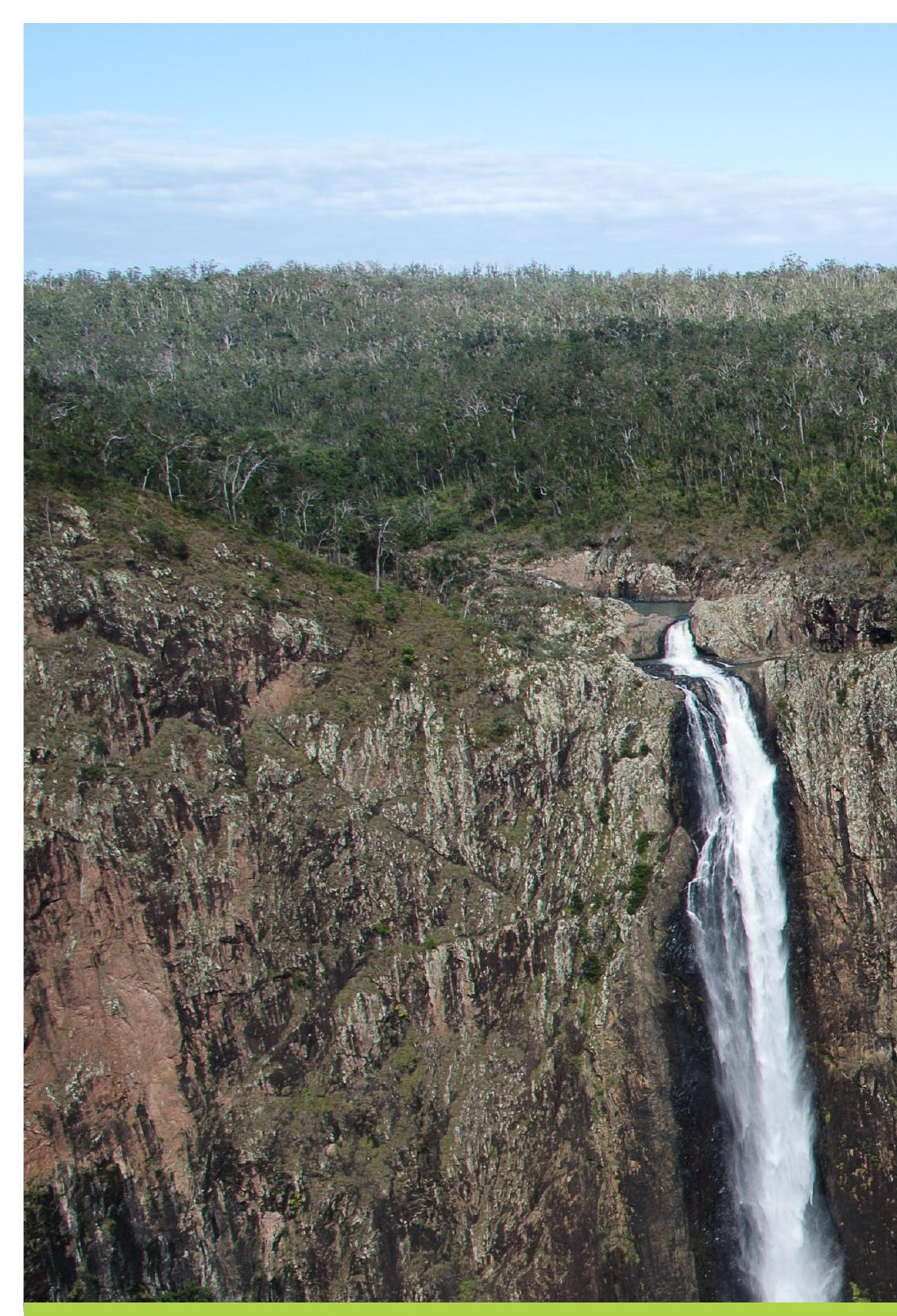

INTERNATIONAL UNION

FOR CONSERVATION OF NATURE

Global Ecosystem Management Programme Rue Mauverney 28

1196 Gland

Switzerland

Tel +41 229990000

Fax +41229990002

www.iucn.org 